DOI: $12737 / 25187$

УДК 630*266: 630*521.1

ПРОГНОЗ СТРОЕНИЯ ЗАЩИТНЫХ ЛЕСОПОЛОС СРЕДНЕЙ СИБИРИ

С УЧЕТОМ АГРОТЕХНИЧЕСКИХ ОСОБЕННОСТЕЙ НАСАЖДЕНИЙ

доктор сельскохозяйственных наук, профессор Г. С. Вараксин ${ }^{1}$

доктор сельскохозяйственных наук, доцент А. А. Вайс ${ }^{2}$

доктор сельскохозяйственных наук, профессор С. Л. Шевелев ${ }^{2}$

кандидат сельскохозяйственных наук П. В. Михайлов²

С. Г. Жалнина ${ }^{3}$

1 - Институт леса им. В.Н. Сукачева СО РАН, Федеральный исследовательский центр

«Красноярский научный центр СО РАН», г. Красноярск, Российская Федерация

2 - ФГБОУ ВО «Сибирский государственный аэрокосмический университет

им. академика М.Ф. Решетнева», г. Красноярск, Российская Федерация

3 - Филиал ФГУП «Рослесинфорг» «Востсиблеспроект», г. Красноярск, Российская Федерация

В основу изучения строения были положены ряды распределения по ступеням толщины. Измерения проводились в защитных лесополосах южной части Средней Сибири. На территории Республики Хакасия (УстьАбаканский, Бейский, Ширинский, Шушенский районы), Красноярского края (Минусинский район) и Республики Тыва (Кызыльский район) были заложены пробные площади. Аппроксимация рядов распределения по диаметру проводилась двумя функциями: нормального распределения и Вейбулла. Применительно к защитным лесополосам для большинства насаждений строение по диаметру адекватнее аппроксимировалось нормальным распределением, что указывало на симметричность рядов. Но при этом функция Вейбулла характеризуется высокой теснотой связи своих коэффициентов с параметрами насаждений, в частности со средним диаметром и нормированной изменчивостью. На основе изучения строения насаждений по диаметру были выявлены оптимальные агротехнические показатели для выращивания насаждений, представленных различными древесными породами. Рекомендуется, прежде чем осуществлять прогнозирование рядов, делить их на две группы. Первая категория отражает влияние внутренних (ростовых) процессов: прироста, отпада, перемещения деревьев по ступеням. Данные ряды можно прогнозировать с учетом среднего диаметра древостоя и теоретической густоты (площади питания отдельного дерева). Вторая группа рядов сформировалась под влиянием внешних факторов (дополнение, возобновление, рубки, лесные пожары).Эти ряды прогнозируются с учетом среднего диаметра и стандартного отклонения деревьев. Для прогноза строения насаждений из лиственницы сибирской, березы повислой, вяза приземистого и тополя черного получены модели на основе функции Вейбулла.

Ключевые слова: лесные полосы, строение по диаметру, агротехнические показатели, прогнозирование. 


\title{
FORECAST OF THE STRUCTURE OF SHELTERBELTS IN THE CENTRAL SIBERIA TAKING INTO ACCOUNT AGRONOMIC CHARACTERISTICS OF PLANTATIONS
}

\author{
DSc in Agriculture, Professor G. S. Varaksin ${ }^{1}$
}

DSc in Agriculture, Associate Professor A. A. Vais ${ }^{2}$

DSc in Agriculture, Professor S. L. Shevelev ${ }^{2}$

$\mathrm{PhD}$ in Agriculture P. V. Mikhailov ${ }^{2}$

S. G. Zhalnina ${ }^{3}$

1 - V.N. Sukachev Institute of Forest, SB RAS, Federal research center «Krasnoyarsk scientific centre of SB RAS», Krasnoyarsk, Russian Federation

2- Federal State Budget Education Institution of Higher Education «Siberian State Aerospace University named after academic M.F. Reshetnev», Krasnoyarsk, Russian Federation

3 - The branch of Federal State Unitary Enterprise «Roslesinforg» «Vostsiblesproekt», Krasnoyarsk, Russian Federation

\begin{abstract}
The study of the structure was based on a series of distribution by the steps of the thickness. Measurements were carried out in forest shelter belts of the southern part of Central Siberia. Plots were laid on the territory of the Republic of Khakassia (UstAbakan, Bay, Shirinsky, Shushensky districts), Krasnoyarsk territory (Minusinsk district) and the Republic of Tuva (Kyzylskiy district). Approximation of distribution rows by diameter has been implemented by two functions: normal distribution and Weibull distribution. With respect to protective forest belts for most forest stands, structure by diameter is more adequately approximated by normal distribution, indicating the symmetry rows. But at this, function of Weibull is characterized by high correlation of its ratios with parameters of plantations, in particular with average diameter and normalized variability. Based on the study of the structure of the plantings in diameter, the optimal agro-technical indicators for the cultivation of plantations presented a variety of wood species, were revealed. It is recommended to divide rows into two groups, before forecasting the series. The first category reflects the influence of the internal (growth) processes: growth, mortality, movement of trees on the steps. These rows can be predicted taking into account the average diameter of tree stand and theoretical density (square of nutrition of individual tree). The second group of rows was formed under the influence of external factors (supplement, renewal, felling, and forest fires).These rows are forecasted using the average diameter and standard deviation of trees. For the prediction of the structure of the stands of Siberian larch, silver birch, Siberian elm and black poplar, model based on the Weibull function, were obtained.
\end{abstract}

Keywords: forest belts, structure on diameter, agronomic indicators, forecasting.

\section{Введение}

В последнее время важным аспектом развития защитного лесоразведения является повышение долговечности, сохранение устойчивости агроценозов, связанных с многофункциональностью и биосферной ролью этих посадок, особенно в аридных условиях [1, 2]. Актуальность проблемы обоснована практически отсутствием публикаций, исследующих строение защитных лесополос в аридных условиях.

Теория строения естественных древостоев остается актуальной проблемой лесной таксации. При этом определение понятия «строение» все время трансформируется в соответствии с уровнем развития научных знаний. П.М. Верхунов [3] под строением понимал совокупное сочетание характера варьирования таксационных показателей, распределения деревьев по ним и соотношения этих показателей между собой на определенных возрастных этапах развития леса. Основой теории строения древостоев, по мнению автора, являлось распределение деревьев по диаметру. В.Ф. Лебков [4] рассматривал строение как состав и пространственное расположение элементарных частей, на которые расчленяется древостой и которые находят выражение в особенностях рядов распределения стволов по основным таксационным показателям. Развивая теорию строения, автор предложил выделять типы строения. Ученый выделяет пять факторов, обуславливающих тип строения древостоя: число деревьев на единице площади (густота), равномерность размещения стволов на территории, возрастная структура насаждения, состав пород, занимающих данную территорию, порядок смешения пород, - выделяя при этом густоту. 
А.А. Макаренко [5], указывая на причины динамики строения древостоев, отмечал определяющее влияние на этот процесс прироста и отпада, а также формы начальной кривой распределения, которая зависит от условий произрастания. В.Я. Каплунов [6], анализируя динамику строения одновозрастных сосняков, кроме указанных выше факторов, предлагал учитывать изменение рядов распределений вследствие различия прироста отдельных деревьев.

Обзор литературы позволил констатировать, что для изучения строения насаждений используют две наиболее распространенные функции: Вейбулла и нормального распределения.

\section{Материалы и методы исследований}

Основой исследования являлись перечетные ведомости, отражающие распределение деревьев по абсолютным ступеням толщины. Исследования проводились в защитных лесополосах на территории республики Хакасия (Усть-Абаканский, Бейский, Ширинский, Шушенский районы), Минусинского района Красноярского края и республики Тыва (Кызыльский район). Возраст ценозов варьировался от 26 до 47 лет. Древостои произрастали преимущественно на южных и обыкновенных черноземах, на отдельных участках выявлено засоление и размещение на песчаных почвах. Ассортимент древесных и кустарниковых пород представлен Б - березой повислой(Betula pendula E.), В - вязом приземистым (Ulmus pumila L.), Л - лиственницей сибирской (Larix sibirica L.) (рис. 1), C - сосной обыкновенной (Pinus sylvestris L.), T тополем черным (Populus nigra L.), K - караганой древовидной (Karagana arborescens L.). Защитные полосы по составу были представлены преимущественно однородными, чистыми насаждениями. Однако встречались смешанные древостои из вяза, тополя и караганы, а также массивы из сосны, лиственницы и березы. Число рядов в полосах варьировалось от 1 до 7. Рядовая, шахматная посадка использовалась для деревьев березы, вяза и лиственницы. Схема смешения соответствовала рекомендациям по созданию защитных полос. Густота зависела от принимаемой схемы смешения и последующего отпада растений. Полосы имели различную конструкцию от ажурной до плотной. Характеристика насаждений на пробных площадях указывала на породное и конструктивное многообразие защитных лесополос.

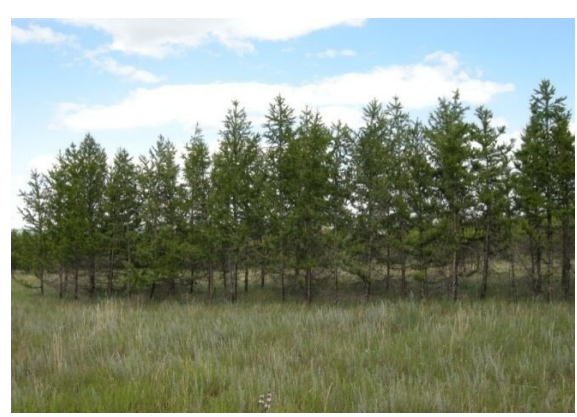

а) рядовое размещение лиственницы

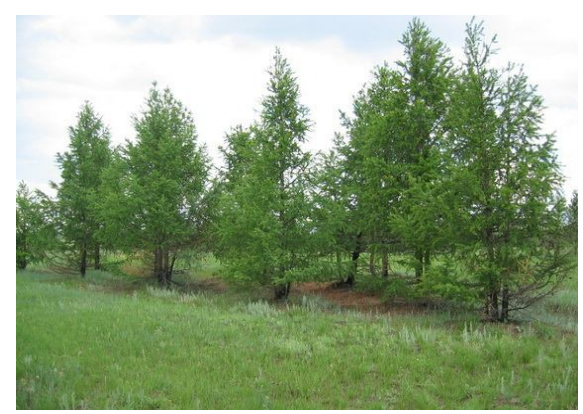

б) шахматное размещение лиственницы

Рис. 1. Водоохранные лесные полосы лиственницы сибирской с различным размещением посадочных мест

По мнению ряда исследователей (В.Я. Каплунов [6], Н.В. Ганина [7], С.Н. Свалов [8]), оптимальной функцией, аппроксимирующей ряды распределения, является функция Вейбулла, коэффициенты которой, с одной стороны, отражают процессы прироста и отпада, с другой стороны, имеют ясную биологическую интерпретацию:

$$
f_{(x)}=\frac{c}{b} \cdot\left[\frac{(x-\theta)}{b}\right]^{(c-1)} \cdot e\left\{-\left[\frac{(x-\theta)}{b}\right]^{c}\right\},
$$

дляุ $\theta<\mathrm{x}, \mathrm{b}>0, \mathrm{c}>0$,

где $\mathrm{b}$ - параметр масштаба распределения,

c - параметр формы, показатель степени и направления асимметрии,

$\theta$ - параметр положения ( $\theta$ соответствует минимальному диаметру древостоя $\theta=\mathrm{d}_{\min }$, где $\theta+\mathrm{b}$ аппроксимирует диаметр, меньше которого расположено $68 \%$ деревьев, при $\theta=0$ распределение двухпараметрическое),

е - основание натурального логарифма (2.71...).

В этой связи данная функция активно используется для прогноза строения естественных насаждений [9]. В последние годы широко стала использоваться степенная функция для выравнивания рядов с преобла- 
дающей световой конкуренцией $[10,11,12]$. Уравнение Гаусса также используется при биологических исследованиях, как пример гипотетического «идеального распределения» [9]

$$
f_{(x)}=\frac{1}{\sigma \cdot \sqrt{2 \pi}} \cdot e^{-\frac{\left(x_{i}-\bar{x}\right)^{2}}{2 \sigma^{2}}},
$$

где $\mathrm{f}(\mathrm{x})$ - вероятность появления значения $\mathrm{x}$,

$\pi-$ постоянная величина, $3,1412 \ldots$,

$\sigma$ - среднеквадратическое отклонение,

$\mathrm{X}_{\mathrm{i}}-\mathrm{X}_{\mathrm{cp}}$ - расстояние от любого значения переменной величины и среднего арифметического значения.

Обработка рядов выполнялась с помощью статистического пакета «STATISTICA», опцией нелинейной оценки.

\section{Результаты и их обсуждение}

Ряды распределения позволяют помимо прогноза размеров деревьев определить устойчивость насаждений, учитывая динамику коэффициентов, среднюю величину и стандартное отклонение. В табл. 1 приведены значения указанных выше показателей по древесным породам и пробным площадям.

Согласно характеристике кривой нормального распределения среднее значение варьировалось в следующих пределах: лиственница сибирская ( $\mathrm{x}_{\mathrm{cp}}=7,5$ 19,3 см), сосна обыкновенная ( $\left.\mathrm{x}_{\mathrm{cp}}=12,5-21,1 \mathrm{~cm}\right)$, береза повислая ( $\mathrm{x}_{\mathrm{cp}}=12,1-14,2$ см), вяз приземистый $\left(\mathrm{x}_{\mathrm{cp}}=6,4-\right.$ 15,0 см), тополь черный $\left(\mathrm{x}_{\mathrm{cp}}=11,4-26,6\right.$ см). Стандартное отклонение для всех пород менялось в пределах 1,87-9,39 см. Неоднородным строением характеризовался тополь черный, поскольку $\sigma=4,91-9,39$ см. В большинстве случаев соответствие рядов нормальному распределению превышало критическое значение 0,95 и более адекватно выравнивало распределение по диаметру, чем функция Вейбулла (табл. 1). Параметр масштаба (b) имел тесную линейную связь со средними значениями рядов $[9,10]$. Поэтому изменчивость коэффициента аналогична приведенным выше лимитам средних значений по породам. Параметр формы (c) тесно связан со среднеквадратическим отклонением [9, 10]. Данный коэффициент отражает совокупное влияние статистических показателей (асимметрии, эксцесca, среднего значения, стандартного отклонения). Изменчивость показателя по породам следующая: лиственница сибирская (с = 2,298-11,464), сосна обыкновенная (c = 4,070-8,172), береза повислая ( $=3,181$ $5,912)$, вяз приземистый (c = 2,254-3,771), тополь чер- ный (c=1,828-4,350).

В контексте данной статьи необходимо выявить агротехнические особенности насаждений, имеющих различное строение. С этой целью все лесополосы были дифференцированы по породам, значениям центра ряда распределения (среднего арифметического) и стандартному отклонению (ранжировано в баллах от минимальной до максимальной величины) (табл. 2).

В качестве первичной гипотезы принималось, что наиболее благоприятные условия созданы в защитных насаждениях, имеющих максимальное среднее значение по диаметру стволов и минимальное стандартное отклонение с учетом возраста. Результаты анализа показали следующее.

Лиственница сибирская (Шира). Оптимальные агротехнические показатели: рядовая 4-рядная посадка со схемой смешения $3 \cdot 0,65$ м.

Лиственница сибирская (Соленоозерск). Оптимальные агротехнические показатели: шахматная или рядовая посадка со сплошной вспашкой и уходами до 7 лет, схема посадки 4·1,5 м или $2 \cdot 6$ м.

Береза повислая. Оптимальные агротехнические показатели: шахматная посадка со схемой посадки $2 \cdot 6$ м.

Вяз приземистый. Оптимальные агротехнические показатели: шахматный способ создания со схемой смешения 2.6 м и однорядные полосы со схемой посадки $1 \cdot 1,5$ м.

Лиственница сибирская. Оптимальные агротехнические показатели: шахматный способ создания со схемой смешения $2 \cdot 6$ м и однорядные полосы со схемой посадки 1·1,5 м.

Тополь черный. Оптимальные агротехнические показатели: почвы - обыкновенные черноземы. Рядовая посадка со схемой смешения $3 \cdot 1,5$ м в чистом насаждении.

На строение древостоев оказывает влияние совокупность факторов, главными из которых являются прирост и изреживание деревьев. Проецируя эти факторы на коэффициенты функции Вейбулла, ряд исследователей установили $[6,7]$ наличие высокого уровеня связи коэффициента масштаба (b) со средним диаметром, а коэффициента формы (c) с изменчивостью признака по отношению к среднему значению $\left(\sigma / \mathrm{d}_{\mathrm{cp}}\right)$. Данные связи позволяют с высокой степенью адекватности прогнозировать строение по диаметру естественных и искусственных насаждений. Показатель, который может отражать влияние процесса отпада на ряд 


\section{Естественные науки и лес}

Таблица 1

Показатели рядов распределений по диаметру защитных лесополос южной части Средней Сибири

\begin{tabular}{|c|c|c|c|c|c|c|}
\hline \multirow{3}{*}{ Порода } & \multicolumn{3}{|c|}{ Функция Вейбулла } & \multicolumn{3}{|c|}{ Функция нормального распределения } \\
\hline & \multicolumn{2}{|c|}{ коэффициенты } & \multirow{2}{*}{$\mathrm{R}$} & \multicolumn{2}{|c|}{ показатели } & \multirow[t]{2}{*}{$\mathrm{R}$} \\
\hline & $\mathrm{b}$ & $\mathrm{c}$ & & $\mathrm{X}_{\mathrm{cp}}$ & $\sigma$ & \\
\hline \multicolumn{7}{|c|}{ Шира } \\
\hline Л & 8,624 & 2,906 & 0,96 & 7,5 & 3,12 & 0,97 \\
\hline Л & 9,008 & 3,205 & 0,95 & 8,0 & 2,92 & 0,95 \\
\hline$\pi$ & 8,879 & 3,032 & 0,96 & 7,8 & 3,05 & 0,97 \\
\hline Л & 9,028 & 2,298 & 0,95 & 7,4 & 3,84 & 0,97 \\
\hline Л & 10,002 & 3,120 & 0,96 & 8,8 & 3,33 & 0,97 \\
\hline \multicolumn{7}{|c|}{ Соленоозерное } \\
\hline Л & 11,906 & 5,332 & 0,99 & 11,2 & 2,35 & 0,99 \\
\hline Л & 12,528 & 7,189 & 0,99 & 12,0 & 1,89 & 0,99 \\
\hline$\pi$ & 14,694 & 8,591 & 0,99 & 14,2 & 1,87 & 0,99 \\
\hline Л & 20,570 & 5,383 & 0,99 & 19,3 & 4,02 & 0,99 \\
\hline Л & 17,841 & 9,232 & 0,99 & 17,0 & 2,49 & 0,99 \\
\hline$\pi$ & 18,419 & 11,464 & 0,99 & 18,0 & 2,52 & 0,99 \\
\hline $\mathrm{C}$ & 21,857 & 8,172 & 0,99 & 21,1 & 3,12 & 0,99 \\
\hline \multicolumn{7}{|c|}{ Лесополоса } \\
\hline Б & 14,718 & 5,836 & 0,99 & 13,9 & 2,72 & 0,99 \\
\hline Б & 14,869 & 5,104 & 0,99 & 13,9 & 3,04 & 0,99 \\
\hline Б & 14,141 & 5,912 & 0,98 & 13,4 & 2,55 & 0,87 \\
\hline Б & 12,911 & 4,843 & 0,90 & 12,1 & 2,71 & 0,92 \\
\hline Б & 16,015 & 3,181 & 0,65 & 14,2 & 5,36 & 0,65 \\
\hline $\mathrm{C}$ & 13,587 & 4,084 & 0,89 & 12,5 & 3,41 & 0,91 \\
\hline $\mathrm{C}$ & 14,075 & 4,070 & 0,84 & 12,9 & 3,67 & 0,79 \\
\hline B & 16,275 & 2,910 & 0,83 & 14,2 & 5,76 & 0,85 \\
\hline B & 11,729 & 3,126 & 0,94 & 10,3 & 3,72 & 0,94 \\
\hline B & 13,002 & 3,289 & 0,95 & 11,6 & 4,10 & 0,96 \\
\hline B & 16,549 & 3,771 & 0,99 & 15,0 & 4,61 & 0,99 \\
\hline B & 7,559 & 2,607 & 0,96 & 6,4 & 2,86 & 0,96 \\
\hline B & 8,439 & 2,738 & 0,97 & 7,3 & 3,10 & 0,98 \\
\hline B & 8,543 & 2,254 & 0,97 & 7,0 & 3,71 & 0,98 \\
\hline $\mathrm{B}$ & 9,176 & 3,018 & 0,95 & 8,1 & 3,18 & 0,96 \\
\hline Л & 13,097 & 3,821 & 0,98 & 11,9 & 3,59 & 0,98 \\
\hline Л & 13,198 & 3,702 & 0,95 & 11,9 & 3,82 & 0,95 \\
\hline Л & 16,897 & 4,840 & 0,94 & 15,8 & 3,69 & 0,94 \\
\hline$\pi$ & 18,147 & 6,350 & 0,97 & 17,3 & 3,03 & 0,96 \\
\hline Л & 12,767 & 2,998 & 0,82 & 11,2 & 4,29 & 0,81 \\
\hline Л & 14,932 & 4,101 & 0,89 & 13,7 & 3,93 & 0,88 \\
\hline Л & 14,922 & 4,620 & 0,96 & 13,9 & 3,35 & 0,97 \\
\hline Л & 17,770 & 8,657 & 0,99 & 16,9 & 2,57 & 0,99 \\
\hline $\mathrm{T}$ & 14,722 & 1,828 & 0,71 & 11,4 & 7,41 & 0,68 \\
\hline $\mathrm{T}$ & 15,936 & 3,308 & 0,92 & 14,2 & 4,91 & 0,92 \\
\hline $\mathrm{T}$ & 28,747 & 4,350 & 0,98 & 26,6 & 6,89 & 0,99 \\
\hline $\mathrm{T}$ & 18,137 & 2,279 & 0,95 & 14,9 & 7,71 & 0,95 \\
\hline $\mathrm{T}$ & 21,655 & 2,254 & 0,97 & 17,9 & 0,39 & 0,96 \\
\hline
\end{tabular}

распределения по диаметру - густота. В дальнейших исследованиях использовали три вида густоты: начальная, текущая и теоретическая, вычисленная исходя из площади питания одного дерева:

$$
N_{\text {meop }}=\frac{10000}{S_{\Pi}},
$$

где $\mathrm{N}_{\text {теор }}$ - теоретическая густота, шт./га,

$\mathrm{S}_{\text {п }}$ - площадь питания одного дерева (шаг посадки * расстояние между рядами), м². $^{2}$. 


\section{Естественные науки и лес}

Таблица 2

Агротехнические особенности и строение защитных насаждений южной части Средней Сибири

\begin{tabular}{|c|c|c|c|c|c|c|c|}
\hline \multicolumn{2}{|c|}{ Статистика } & \multicolumn{6}{|c|}{ Агротехнические показатели } \\
\hline $\mathrm{X}_{\mathrm{cp}}$ & $\begin{array}{c}\sigma \\
\text { в баллах }\end{array}$ & $\begin{array}{l}\text { возраст, } \\
\text { лет }\end{array}$ & почва & $\begin{array}{c}\text { способ } \\
\text { создания }\end{array}$ & $\begin{array}{l}\text { число } \\
\text { рядов }\end{array}$ & \begin{tabular}{c|} 
схема \\
смешения
\end{tabular} & особенности \\
\hline 1 & 2 & 3 & 4 & 5 & 6 & 7 & 8 \\
\hline \multicolumn{8}{|c|}{ Шира (лиственница сибирская) } \\
\hline 8,8 & 4 & 20 & - & $\mathrm{P}$ & 4 & $3 * 0,65$ & Направление полосы ЮВ $30^{0}$ \\
\hline 8,0 & 1 & 20 & - & $\mathrm{P}$ & 4 & $3 * 0,65$ & Направление полосы Ю3 30 \\
\hline 7,8 & 2 & 20 & - & $P$ & 4 & $3 * 0,65$ & Направление полосы ЮВ $30^{0}$ \\
\hline 7,5 & 3 & 20 & - & Ш & 6 & $2 * 0,65$ & $\begin{array}{c}\text { Слабый низовой пожар, сплошная обработка почвы, направление } \\
\text { полосы ЮВ } 55^{\circ}\end{array}$ \\
\hline 7,4 & 5 & 20 & - & $\mathrm{P}$ & 4 & $3 * 0,8$ & Мелкая обработка почвы, направление полосы ЮВ $55^{0}$ \\
\hline \multicolumn{8}{|c|}{ Соленоозерное (лиственница сибирская) } \\
\hline 19,3 & 6 & 40 & OЧC & Ш & 4 & $4 * 1,5$ & $\begin{array}{c}\text { Сплошная вспашка со щелеванием, агротехнические уходы до } \\
18 \text { лет, вертикально-продуваемая конструкция, направление } \\
\text { полосы Ю3 }\end{array}$ \\
\hline 18,0 & 5 & 39 & ЮЧ & Ш & 4 & $2 * 6$ & $\begin{array}{c}\text { Сплошная вспашка, агротехнические уходы до } 18 \text { лет, вертикаль- } \\
\text { но-продуваемая конструкция, направление полосы ЮВ }\end{array}$ \\
\hline 17,0 & 4 & 39 & $\begin{array}{c}\text { ЮЧМ } \\
\mathrm{C}\end{array}$ & Ш & 4 & $2 * 6$ & $\begin{array}{c}\text { Сплошная вспашка со щелеванием, агротехнические уходы до } \\
18 \text { лет, вертикально-продуваемая конструкция, направление } \\
\text { полосы Ю3 }\end{array}$ \\
\hline 14,2 & 1 & 22 & ЮЧС & Ш & 4 & $4 * 5,0$ & $\begin{array}{c}\text { Сплошная вспашка, агротехнические уходы до } 7 \text { лет, вертикально- } \\
\text { продуваемая конструкция, направление полосы С }\end{array}$ \\
\hline 12,0 & 2 & 22 & ЮЧС & $\mathrm{P}$ & 4 & $4 * 1,5$ & $\begin{array}{c}\text { Сплошная вспашка, агротехнические уходы до } 7 \text { лет, диагонально- } \\
\text { крупносетчатая конструкция, направление полосы С }\end{array}$ \\
\hline 11,2 & 3 & 22 & ЮЧС & $\mathrm{P}$ & 4 & $4 * 1,5$ & $\begin{array}{c}\text { Сплошная вспашка, агротехнические уходы до } 7 \text { лет, плотная кон- } \\
\text { струкция, направление полосы C }\end{array}$ \\
\hline 14,2 & 5 & 38 & ЧС & $\mathrm{P}$ & 2 & $3 * 0,75$ & $\begin{array}{c}\text { Смешанное насаждение, компактныйлесной массив, многолетний } \\
\text { опыт с внесением удобрений, направление полосы ЮВ } 38^{0}\end{array}$ \\
\hline \multicolumn{8}{|c|}{ Береза повислая } \\
\hline 14,0 & 4 & 27 & ЮЧ & $\mathrm{P}$ & 2 & $7 * 1,5$ & Продуваемая конструкция, направление полосы С3 $75^{\circ}$ \\
\hline 13,9 & 3 & 27 & ЮЧ & $\mathrm{P}$ & & $3 * 1,5$ & $\begin{array}{c}\text { Продуваемая конструкция, самовольная рубка для заготовки вени- } \\
\text { ков, направление полосы С3 } 75^{\circ}\end{array}$ \\
\hline 13,4 & 1 & 27 & ЮЧ & Ш & 4 & $2 * 6$ & $\begin{array}{l}\text { Вертикально-продуваемая конструкция, направление полосы } \\
\text { С3 } 75^{\circ}\end{array}$ \\
\hline 12,1 & 2 & 38 & ЧС & $\mathrm{P}$ & 2 & $3 * 0,75$ & $\begin{array}{c}\text { Смешанное насаждение, компактный лесной массив, многолетний } \\
\text { опыт с внесением удобрений, направление полосы ЮВ } 38^{0}\end{array}$ \\
\hline \multicolumn{8}{|c|}{ Вяз приземистый } \\
\hline 15,0 & 7 & 27 & ЮЧ & Ш & 4 & $2 * 6$ & Вертикально-продуваемая конструкция \\
\hline 14,2 & 8 & 29 & ЮЧЗ & $\mathrm{P}$ & 1 & $1 * 1,5$ & 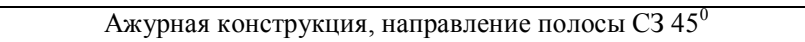 \\
\hline 11,6 & 6 & 27 & ЮЧ & $\mathrm{P}$ & 2 & $2 * 6$ & Продуваемая конструкция \\
\hline 10,4 & 5 & 27 & ЮЧ & $\mathrm{P}$ & 3 & $3 * 1,5$ & Продуваемая конструкция, направление полосы С3 $45^{\circ}$ \\
\hline 8,1 & 3 & 27 & ЮЧ & $\mathrm{P}$ & 7 & $3 * 1,5$ & Смешанное насаждение, плотная конструкция \\
\hline 7,3 & 2 & 29 & ЮЧ & $\mathrm{P}$ & 4 & $3 * 1,0$ & Ажурная конструкция, ровное местоположение \\
\hline 7,0 & 4 & 26 & ЮЧ & $\mathrm{P}$ & 7 & $4 * 1,5$ & Смешанное насаждение, плотная конструкция \\
\hline 6,4 & 1 & 29 & ЮЧ & $\mathrm{P}$ & 4 & $3 * 1,0$ & Ажурная конструкция, направление полосы Ю3 $10^{\circ}$ \\
\hline \multicolumn{8}{|c|}{ Лиственница сибирская } \\
\hline 17,3 & 2 & - & ЮЧ & Ш & 5 & $2 * 6$ & $\begin{array}{c}\text { Вертикально-продуваемая конструкция, направление полосы } \\
\text { ЮВ } 60^{\circ}\end{array}$ \\
\hline 16,9 & 1 & 37 & ЮЧ & Ш & 4 & $2 * 6$ & $\begin{array}{c}\text { Вертикально-продуваемая конструкция, направление полосы } \\
\text { ЮВ } 60^{\circ}\end{array}$ \\
\hline 15,8 & 5 & 29 & ЮЧ & $\mathrm{P}$ & 1 & $1 * 1,5$ & Продуваемая конструкция, направление полосы С3 $45^{\circ}$ \\
\hline 13,9 & 3 & 45 & $\mathrm{4C}$ & $\mathrm{P}$ & 5 & $3 * 0,75$ & Продуваемая конструкция, направление полосы ЮВ 400 \\
\hline
\end{tabular}




\section{Естественные науки и лес}

\begin{tabular}{|c|c|c|c|c|c|c|c|}
\hline 1 & 2 & 3 & 4 & 5 & 6 & 7 & 8 \\
\hline 13,7 & 7 & 34 & ЧС & $\mathrm{P}$ & 2 & $3 * 0,75$ & $\begin{array}{c}\text { Смешанное насаждение, компактный лесной массив, многолетний опыт с внесени- } \\
\text { ем удобрений, направление полосы ЮВ } 38^{\circ}\end{array}$ \\
\hline 11,9 & 6 & - & ЮЧ & $\mathrm{P}$ & 3 & $4 * 3$ & Продуваемая конструкция \\
\hline 11,9 & 4 & - & ЮЧ & Ш & 4 & $2 * 6$ & Вертикально-продуваемая конструкция \\
\hline 11,2 & 8 & 34 & ЧС & $\mathrm{P}$ & 2 & $3 * 0,75$ & $\begin{array}{c}\text { Смешанное насаждение, компактный лесной массив, многолетний опыт с внесени- } \\
\text { ем удобрений, направление полосы ЮВ } 38^{\circ}\end{array}$ \\
\hline \multicolumn{8}{|r|}{ Тополь черный } \\
\hline 26,6 & 2 & - & $\mathrm{OY}$ & $\mathrm{P}$ & 4 & $3 * 1,5$ & Продуктивная лесополоса продуваемой конструкции, направление полосы Ю \\
\hline 17,9 & 5 & - & $\mathrm{OY}$ & $\mathrm{P}$ & 4 & $3 * 1,5$ & Продуваемая конструкция, направление полосы С $342^{0}$ \\
\hline 14,9 & 4 & - & $\mathrm{OY}$ & $\mathrm{P}$ & 4 & $3 * 1,5$ & Продуваемая конструкция, направление полосы С $345^{0}$ \\
\hline 14,2 & 1 & 27 & ЮЧ & $\mathrm{P}$ & 7 & $3 * 1,5$ & Смешанное насаждение, плотная конструкция \\
\hline 11,4 & 3 & 26 & ЮЧ & $\mathrm{P}$ & 7 & $4 * 1,5$ & Смешанное насаждение, плотная конструкция \\
\hline
\end{tabular}

Примечание: $\mathrm{X}_{\text {cp. }}$ - средняя величина ряда распределения, см; $\sigma$ - стандартное отклонение в баллах.

Способ создания: Р - рядовой ; Ш - шахматный. Почва: ОЧ - обыкновенный чернозем; ЮЧ - южный чернозем; ЧС - чернозем среднесуглинистый; ЮЧЗ - южный чернозем с вторичным засолением; ЮЧС - южный чернозем среднесуглинистый; ОЧС - обыкновенный чернозем среднесуглинистый; ЮЧМС - южный чернозем малогумусный среднесуглинистый

В результате было установлено, что применительно к полезащитным полосам именно теоретическая густота характеризовалась максимальным влиянием на коэффициент формы (функция Вейбулла). В окончательном варианте для прогноза рядов распределения по диаметру были использованы связи $\mathrm{b}=\mathrm{f}\left(\mathrm{d}_{\mathrm{cp}}\right), \mathrm{c}=\mathrm{f}$ $\left(\mathrm{N}_{\text {теор. }}\right), \mathrm{c}=\mathrm{f}\left(\sigma / \mathrm{d}_{\mathrm{cp}}\right)$ (пример, лесополосы из лиственницы (Соленоозерное), рис. 2).

Диаграммы отражали регрессионную связь между признаками. На основании данных графиков были выявлены закономерности в строении защитных лесополос.

Лиственница сибирская (Соленоозерное, лесополосы юга Красноярского края). С ростом размеров деревьев по диаметру линейно увеличивается масштаб распределения. Возрастание изменчивости рядов распределения $\left(\sigma / \mathrm{d}_{\mathrm{cp}}\right)$ способствует аллометрическому уменьшению степени асимметричности ряда по диаметру.

Береза повислая. С увеличением размеров деревьев и густоты лесополос линейно растет, с одной стороны, масштаб распределения, и линейно уменьшаются параметры формы ряда распределения - с другой стороны.

Вяз приземистьй. Наблюдается выраженный линейный рост масштаба распределения с изменением среднего диаметра. Увеличение густоты лесополос формирует незначительное линейное
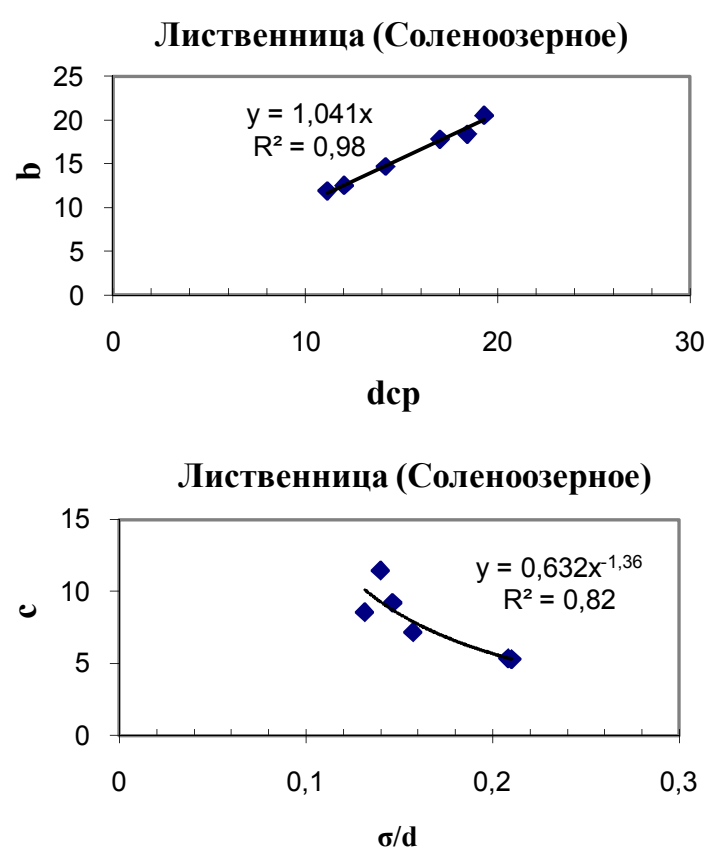

Рис. 2. Связь коэффициентов функции Вейбулла с показателями насаждений

уменьшение степени асимметричности рядов.

Тополь черный. Рост деревьев по диаметру линейно увеличивает размах варьирования. При этом возрастание изменчивости рядов способствует аллометрическому уменьшению асимметричности рядов распределения. 


\section{Естественные науки и лес}

Невысокий уровень связи у лиственницы сибирской в лесополосах юга Красноярского края можно объяснить агротехническими особенностями насаждений (низкая густота с рядовой и шахматной посадкой деревьев). Тополь черный характеризуется неоднородной структурой (строением), что объясняется влиянием целого ряда факторов (дополнение, рубки ухода, лесные пожары). В связи с этим применительно к этим насаждениям использовали зависимость $\mathrm{c}=\mathrm{f}(\sigma / \mathrm{dcp}$.). Оценка полученных уравнений представлена в табл. 3.

Коэффициент масштаба (b) адекватно аппроксимировался одно и двух коэффициентными линейными моделями. Форма рядов распределения (с) выравнивалась (лиственница (Шира), береза и вяз)) с помощью линейной связи с теоретической густотой. Для тополя и лиственницы из Соленоозерное и лесополос Средней Сибири коэффициент формы определялся с помощью степенного нелинейного уравнения через величину $\sigma / \mathrm{d}_{\mathrm{cp}}$.
Уравнение функции Вейбулла для прогноза строения защитных насаждений соответствовало следующему виду [8]:

$$
N_{c m}=N_{\text {оби. }} \cdot a \cdot \frac{c}{d} \cdot\left(\left(\frac{d_{c m}{ }^{(c-1)}}{b}\right) \cdot e^{\left(\frac{d_{c m}}{b}\right)^{a}}\right),
$$

где $\mathrm{N}_{\text {ст }}$ - число деревьев в ступени, шт,

а-размер ступени толщины, см,

$\mathrm{N}_{\text {общ. }}$ - общее число деревьев для данного распределения, шт,

$\mathrm{d}_{\mathrm{cт}}-$ диаметр ступени толщины, $\mathrm{cm}$,

$\mathrm{b}$ - параметр масштаба,

c - параметр формы.

Итоговые модели для различных древесных пород и районов имели следующий вид:

Лиственница (Шира)

$$
\begin{aligned}
& N_{c m}=N_{\text {общ. }} \cdot a \cdot\left(\frac{2,194+0,000176 \cdot N_{T}}{1,1505 \cdot d_{c p}}\right) . \\
& \cdot\left({\frac{d_{c m}}{1,1505 \cdot d_{c p}}}^{\left(2,194+0,000176 \cdot N_{T}\right)-1}\right) \cdot e^{\left(\frac{d_{c m}}{1,1505^{*} d_{c p}}\right)^{a}}
\end{aligned}
$$

\begin{tabular}{|c|c|c|c|c|c|}
\hline \multirow[b]{2}{*}{ Модель } & \multicolumn{2}{|c|}{ Коэффициент } & \multirow[b]{2}{*}{$\mathrm{R}^{2}$} & \multirow{2}{*}{$\begin{array}{c}\text { Основная } \\
\text { ошибка }\end{array}$} & \multirow{2}{*}{$\begin{array}{c}\text { Уровень } \\
\text { значимости (p) } \\
\text { коэффициентов }\end{array}$} \\
\hline & $\mathrm{a}$ & $\mathrm{b}$ & & & \\
\hline \multicolumn{6}{|c|}{ Лиственница (Шира) } \\
\hline $\mathrm{b}=\mathrm{a}+\mathrm{b} * \mathrm{~d}$ & - & 1,1505 & 0,99 & 0,262 & 3н. \\
\hline $\mathrm{c}=\mathrm{a}+\mathrm{b} * \mathrm{~N}_{\text {теор. }}$ & 2,194 & 0,000176 & 0,83 & 0,174 & $3 \mathrm{H}$. \\
\hline \multicolumn{6}{|c|}{ Лиственница (Соленоозерное) } \\
\hline $\mathrm{b}=\mathrm{a}+\mathrm{b} * \mathrm{~d}$ & - & 1,0414 & 0,99 & 0,430 & $3 \mathrm{H}$. \\
\hline $\mathrm{c}=\mathrm{a}^{*}\left(\sigma / \mathrm{d}_{\mathrm{cp}}\right)^{\mathrm{b}}$ & 0,6321 & $-1,368$ & 0,82 & - & - \\
\hline \multicolumn{6}{|c|}{ Лиственница (лесополоса) } \\
\hline $\mathrm{b}=\mathrm{a}+\mathrm{b} * \mathrm{~d}$ & 3,059 & 0,855 & 0,98 & 0,317 & $3 \mathrm{H}$. \\
\hline $\mathrm{c}=\mathrm{a}^{*}\left(\sigma / \mathrm{d}_{\mathrm{cp.}}\right)^{\mathrm{b}}$ & 1,1283 & $-1,0425$ & 0,95 & - & - \\
\hline \multicolumn{6}{|c|}{ Береза (лесополоса) } \\
\hline $\mathrm{b}=\mathrm{a}+\mathrm{b} * \mathrm{~d}$ & - & 1,0761 & 0,99 & 0,422 & 3H. \\
\hline $\mathrm{c}=\mathrm{a}+\mathrm{b} * \mathrm{~N}_{\text {теор }}$ & 6,3726 & $-0,00054$ & 0,71 & 0,686 & $3 \mathrm{H}$. \\
\hline \multicolumn{6}{|c|}{ Вяз (лесополоса) } \\
\hline $\mathrm{b}=\mathrm{a}+\mathrm{b} * \mathrm{~d}$ & 0,748 & 1,0680 & 0,99 & 0,257 & $3 \mathrm{H}$. \\
\hline $\mathrm{c}=\mathrm{a}+\mathrm{b} * \mathrm{~N}_{\text {теор }}$ & 3,696 & $-0,00038$ & 0,60 & 0,344 & $3 \mathrm{H}$. \\
\hline \multicolumn{6}{|c|}{ Тополь (лесополоса) } \\
\hline $\mathrm{b}=\mathrm{a}+\mathrm{b} * \mathrm{~d}$ & - & 1,1484 & 0,99 & 1,449 & $3 \mathrm{H}$. \\
\hline $\mathrm{c}=\mathrm{a}^{*}\left(\sigma / \mathrm{d}_{\mathrm{cp}}\right)^{\mathrm{b}}$ & 1,2273 & $-0,936$ & 0,99 & - & - \\
\hline
\end{tabular}

Таблица 3

Оценка моделей связи коэффициентов Вейбулла с показателями насаждений

Примечание: $\mathrm{R}^{2}$ - коэффициент детерминации; значимость коэффициентов подтверждается соотношением $\mathrm{p}<0.05$ 


\section{Естественные науки и лес}

$$
\begin{aligned}
& \text { Лиственница (Соленоозерное) } \\
& N_{c m}=N_{\text {оби. }} \cdot a \cdot\left(\frac{0,6321 \cdot\left(\frac{\sigma}{d}\right)^{-1,368}}{1,0414 \cdot d_{c p}}\right) . \\
& \cdot\left(\frac{d_{c m}}{1,0414 \cdot d_{c p}}\left(0,6321 \cdot\left(\frac{\sigma}{d}\right)^{-1,368}\right)-1\right) \cdot e^{\left(\frac{d_{c m}}{1,0414 \cdot d_{c p}}\right)^{a}}
\end{aligned}
$$

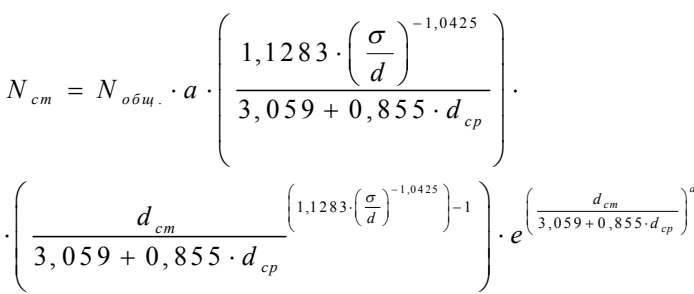

$$
\begin{aligned}
& \text { Береза } \\
& N_{c m}=N_{\text {общ. }} \cdot a \cdot\left(\frac{6,3726-0,00054 \cdot N_{T}}{1,0761 \cdot d_{c p}}\right) \text {. } \\
& \cdot\left({\frac{d_{c m}}{1,0761 \cdot d_{c p}}}^{\left(6,3726-0,00054 \cdot N_{T}\right)-1}\right) \cdot e^{\left(\frac{d_{c m}}{1,0761 \cdot d_{c p}}\right)^{a}} \\
& \text { Вяз } \\
& N_{c m}=N_{\text {оби. }} \cdot a \cdot\left(\frac{3,696-0,00038 \cdot N_{T}}{0,748+1,068 \cdot d_{c p}}\right) . \\
& \cdot\left({\frac{d_{c m}}{0,747+1,068 \cdot d_{c p}}}^{\left(3,696+0,00038 \cdot N_{T}\right)-1}\right) \cdot e^{\left(\frac{d_{c m}}{0,747+1,068 \cdot d_{c p}}\right)^{a}} \\
& \text { Тополь }
\end{aligned}
$$

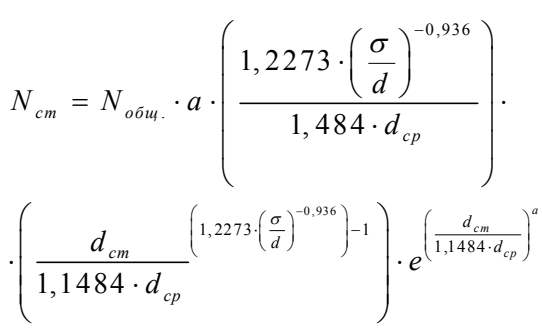

Диапазон действия уравнений соответствует данным, представленным в табл. 1 и пояснениях к ней (см. выше).

\section{Выводы}

Анализ строения защитных лесополос южной части Средней Сибири позволил получить целый ряд выводов:

- на основании обзора литературы установлено две функции, которые целесообразно использовать для изучения строения искусственных насаждений. Это функции нормального распределения и Вейбулла;

- применительно к защитным лесополосам для большинства насаждений строение по диаметру адек- ватнее аппроксимировалось нормальным распределением, что указывало на симметричность рядов;

- функция Вейбулла характеризовалась высокой теснотой связи своих коэффициентов с параметрами насаждений, в частности со средним диаметром и нормированной изменчивостью;

- на основе изучения строения насаждений по диаметру были выявлены оптимальные агротехнические показатели для выращивания насаждений, представленных различными древесными породами;

- в защитных лесополосах различного состава наблюдались однотипные закономерности в соотношениях связей $\mathrm{b}=\mathrm{f}\left(\mathrm{d}_{\mathrm{cp}}\right), \mathrm{c}=\mathrm{f}\left(\mathrm{N}_{\text {теор. }}\right), \mathrm{c}=\left(\sigma / \mathrm{d}_{\mathrm{cp}}\right)$. Исключением являются лесополосы лиственницы п. Шира;

- параметр формы учитывает совокупность внешних (биогенных, антропогенных) и внутренних (ростовых) факторов. Поэтому прежде чем осуществлять прогнозирование рядов, их необходимо разделить на две группы. Первая категория отражает влияние внутренних (ростовых) процессов: прирост, отпад, перемещение деревьев по ступеням. Данные ряды можно прогнозировать с учетом среднего диаметра древостоя и теоретической густоты (площади питания отдельного дерева). Как следует из строения, данной однородной группе соответствуют полосы лиственницы сибирской около п. Шира, березы повислой (лесополосы Средней Сибири), вяза приземистого (лесополосы Средней Сибири). Вторая группа рядов сформировалась под влиянием внешних факторов (дополнение, возобновление, рубки, лесные пожары). Этим насаждениям соответствовали ряды деревьев из лиственницы сибирской района Соленоозерное и лесополосы Средней Сибири, а также тополя черного. Данные ряды прогнозируются с учетом среднего диаметра и стандартного отклонения деревьев.

- параметр масштаба функции Вейбулла аппроксимировали одно- и двухкоэффициентными линейными уравнениями, а коэффициент формы двухкоэффициентными линейными и степенными уравнениями.

- для прогноза строения насаждений из лиственницы сибирской, березы повислой, вяза приземистого и тополя черного получены модели на основе функции Вейбулла. 


\section{Библиографический список}

1. Агролесомелиорация [Текст] / А. Н. Иванов [и др.]. - Изд. 5-е, перераб. - Волгоград : ВНИАЛМИ, 2006. - 746 с.

2. Лобанов, А. И. Состояние полезащитных насаждений и методология создания их нового поколения в Республике Хакасия и южных районах Красноярского края [Текст] / А. И Лобанов, Е. Н. Савин // Экологогеографические аспекты лесообразовательного процесса : матер. Всерос. конф. - Красноярск : Институт леса им. В.Н. Сукачева СО РАН, 2009. - С. 104-107.

3. Верхунов, П. М. Закономерности строения разновозрастных сосняков [Текст] : моногр. / П. М. Верхунов. - Новосибирск : Наука, 1976. - 253 с.

4. Лебков, В. Ф. Типы строения древостоев [Текст] / В. Ф. Лебков // Лесоведение. - 1989. - № 4. C. $12-21$.

5. Макаренко, А. А. О причинах динамики строения древостоев [Текст] / А. А. Макаренко // Лесоведение. - 1972. - № 6. - С. 13-20.

6. Каплунов, В. Я. Анализ динамики одновозрастных сосняков и разработка режимов лесовыращивания [Текст] : автореф. дис. ... канд. с-х. наук : 06.03.02 / В. Я. Каплунов. - Красноярск : ИЛИД, 1987. - 19 с.

7. Ганина, Н. В. Распределение деревьев по диаметру с помощью функции Вейбулла [Текст] / Н. В. Ганина // Лесоведение. - 1984. - № 2. - С. 65-70.

8. Свалов, С. Н. Об оценке пригодности распределения Вейбулла для описания строения древостоев [Текст] / С. Н. Свалов // Вопросы выращивания и рационального лесопользования : сб. ст. - Вып. 139. М. : МЛТИ, 1982. - С. 172-174.

9. Zeide, B. Exponential diameter distribution: interpretation of coefficients [Text] / B. Zeide // Forest Science. - 1984. - Vol. 30. - No.4. - Pp. 907-912.

10. Enquist, B. J. Invariant scaling relations across tree-dominated communities [Text] / B. J. Enquist, K. J. Niklas // Nature. - 2001. - Vol. 410. - No. 5. - Pp. 655-660.

11. Niklas, K. J. Tree size frequency distributions, plant density, age and community disturbance [Text] / K. J. Niklas, J. J. Midgley, R. H. Rand // Ecology letters. - 2003. - No.6. - Pp. 405-411.

12. Shimano, K. A. Power functions for forest structure and regeneration pattern of pioneer and climax species in patch mosaic forests [Text] / K. A. Shimano // Plant Ecology. - 2000. - No. 146. - Pp. 207-220.

\section{References}

1. Ivanov A.N. [et al.]. Agrolesomelioracija [Agrolesomelioration]. Volgograd, 2006, 746 p. (In Russian).

2. Lobanov A.I., Savin E.N. Sostojanie polezashhitnyh nasazhdenij i metodologija sozdanija ih novogo pokolenija v Respublike Hakassija i juzhnyh rajonov Krasnojarskogo kraja [Sostoyaniye of field-protecting plantings and methodology of creation of their new generation in the Republic of Khakassia and the southern areas of Krasnoyarsk edge] Jekologogeograficheskie aspekty lesoobrazovatel'nogo processa: mat. Vserossijskoj konferencii [Ekologo-geografichesky aspects of lesoobrazovatelny process: mat. All-Russian Conference]. Krasnoyarsk, 2009, pp. 104-107. (In Russian).

3. Verkhunov P.M. Zakonomernosti stroenija raznovozrastnyh sosnjakov [Regularities of a structure of unevenage pine forests] Novosibirsk, 1976, 253 p. (In Russian).

4. Lebkov V.F. Tipy stroenija drevostoev [Types of a structure of forest stands] Lesovedenie [Lesovedeniye]. 1989, no. 4, pp. 12-21. (In Russian).

5. Makarenko A.A. O prichinah dinamiki stroenija drevostoev [About the reasons of dynamics of a structure of forest stands] Lesovedenie [Lesovedeniye]. 1972, no. 6, pp. 13-20. (In Russian).

6. Kaplunov V.Ya. Analiz dinamiki odnovozrastnyh sosnjakov i razrabotka rezhimov lesovyrashhivanija avtoref. kand. s-h. nauk [Analysis of the dynamics of even-aged pine forest growing and working condition: abstract Phd in Agricultural]. Krasnoyarsk, 1987, 19 p. (In Russian).

7. Ganina N.V. Raspredelenie derev'ev po diametru s pomoshh'ju funkcii Vejbulla [Distribution of trees on diameter by means of Veybull] Lesovedenie [Lesovedeniye]. 1984, no. 2, pp. 65-70. (In Russian). 


\section{Естественные науки и лес}

8. Slopes S.N. Ob ocenke prigodnosti raspredelenija Vejbulla dlja opisanija stroenija drevostoev [About assessment of suitability of distribution of Veybull for the description of a structure of forest stands] Voprosy vyrashhivanija i racional'nogo lesopol'zovanija: sb. St [Questions of cultivation and rational forest exploitation: collection. thearticles]. Moscow, 1982, Issue 139, pp. 172-174. (In Russian).

9. Zeide B. Exponential diameter distribution: interpretation of coefficients. Forest Science, 1984, Vol. 30, no. 4, pp. 907-912.

10. Enquist B.J., Niklas K.J. Invariant scaling relations across tree-dominated communities. Nature, 2001, Vol. 410, no.5, pp. 655-660.

11. Niklas K. J., Midgley J.J., Rand R.H. Tree size frequency distributions, plant density, age and community disturbance. Ecology letters, 2003, no.6, pp. 405-411.

12. Shimano K.A. Power functions for forest structure and regeneration pattern of pioneer and climax species in patch mosaic forests. Plant Ecology, 2000, no. 146, pp. 207-220.

\section{Сведения об авторах}

Вараксин Геннадий Сергеевич - ведущий научный сотрудник лаборатории лесной таксации и лесопользования Института леса имени В.Н. Сукачева СО РАН, доктор сельскохозяйственных наук, профессор, г. Красноярск, Российская Федерация; e-mail: var@ksc.krasn.ru

Вайс Андрей Андреевич - профессор кафедры лесной таксации, лесоустройства и геодезии ФГБОУ ВО «СибГАУ имени академика М.Ф. Решетнева», доктор сельскохозяйственных наук, доцент, г. Красноярск, Российская Федерация; e-mail: vais6365@mail.ru

Шевелев Сергей Леонидович - заведующий кафедрой лесной таксации, лесоустройства и геодезии ФГБОУ ВО «СибГАУ имени академика М.Ф. Решетнева», доктор сельскохозяйственных наук, профессор, г. Красноярск, Российская Федерация; e-mail: Shevel341@yandex.ru

Михайлов Павел Владимирович - доцент кафедры лесной таксации, лесоустройства и геодезии ФГБОУ ВО «СибГАУ имени академика М.Ф. Решетнева», кандидат сельскохозяйственных наук, г. Красноярск, Российская Федерация; e-mail: mihaylov.p.v@mail.ru

Жалнина Светлана Геннадьевна - инженер первой категории отдела землеустройства Филиала ФГУП «Рослесинфорг» «Востсиблеспроект», г. Красноярск, Российская Федерация; e-mail: var@ksc.krasn.ru

\section{Information about authors}

Varaksin Gennady Sergeevich - Leading Researcher, Laboratory of forest inventory and forest management Institute of Forest of V. N. Sukachyov of the Siberian Branch of the Russian Academy of Science, DSc in Agriculture, Professor, Krasnoyarsk, Russian Federation; e-mail: var@ksc.krasn.ru

Weiss Andrei Andreevich- Professor of Department of forest inventory, forest management and geodesy Federal State Budget Education Institution of Higher Education«SibSAU named after academician M.F. Reshetnev», DSc in Agriculture, Associate Professor, Krasnoyarsk, Russian Federation;e-mail: vais6365@mail.ru

Shevelev Sergey Leonidovich - Head of Department of forest inventory, forest management and geodesy, Federal State Budget Education Institution of Higher Education «SibSA Unamed after academician M.F. Reshetnev», DSc in Agriculture, Professor, Krasnoyarsk, Russian Federation; e-mail: Shevel341@yandex.ru

MikhailovPavelVladimirovich - Associate Professor of Departmentof forest inventory, forest management and geodesy Federal State Budget Education Institution of Higher Education «SibSAU named after academician M.F. Reshetnev», PhD in Agriculture, Krasnoyarsk, Russian Federation; e-mail: mihaylov.p.v@mail.ru

Zhalnina Svetlana Gennadievna - engineer of the first category of land management department East Siberian State Forest Inventory Enterprise Federal State Unitary Enterprise Roslesinforg branch, Krasnoyarsk, Russian Federation; e-mail: var@ksc.krasn.ru 